\title{
Association of the CD226 Genetic Polymorphisms with Risk of Tuberculosis
}

\author{
Hyun-Seok Jin ${ }^{1}$ and Sangjung Park ${ }^{1,2, \uparrow}$ \\ ${ }^{1}$ Department of Biomedical Laboratory Science, College of Life and Health Sciences, \\ Hoseo University, Asan, Chungnam 31499, Korea \\ ${ }^{2}$ The Research Institute for Basic Sciences, Hoseo University, Asan, Chungnam 31499, Korea
}

\begin{abstract}
Tuberculosis (TB), mainly disseminated by infection of the respiratory tract, remains an unsolved community health problem by Mycobacterium tuberculosis (MTB). However, because of the different susceptibility to MTB, people infected with MTB do not all develop TB. These differences of disease arise from individual genetic susceptibility as well as the property of the microorganisms itself. CD226, one of the genetic factors that influences TB, interact with its ligand PVR and ITGB2. It is induced various cellular responses that contribute multiple innate and adaptive responses. In a previous study, CD226 enhanced immune efficacy induced by Ag85A DNA vaccination that is secreted protein by MTB. The aim of this study was to investigate the association between six genetic polymorphisms of CD226 gene and TB status with Korean population. Our results show that two SNPs of CD226 were identified to associate with tuberculosis. The highest significant SNP was rs 17081766 (OR=0.70, CI: $\left.0.54 \sim 0.90, P=5.4 \times 10^{-3}\right)$. According to this study, polymorphisms of CD226 gene affect the outbreak of TB in MTB-infected patients. It is suggested that polymorphism of other genes also associated with immune responses results in susceptibility to TB. The results from this study suggest that not only the characteristics of the microorganism itself but also the genetic background of the individual may affect progression of TB in MTB-infected patients.
\end{abstract}

Key Words: Tuberculosis, Mycobacterium tuberculosis, CD226, Genetic association study

\section{서 론}

결핵은 결핵균(Mycobacterium tuberculosis, MTB) 감염 에 의해 발병하는 질병으로 2015년 한 해 동안 국내에서 32,000 명의 신환자가 발생하고, 2,000 명 이상이 사망한 공 중보건학적 문제를 일으키는 질병이다(KCDC, 2015). 결핵 은 주로 MTB의 호흡기를 통한 감염에 의하여 전파가 되 는데, 질병의 전파 속도가 빠르고 결핵균에 대한 개개인
의 감수성 및 인체의 면역 체계가 다르기 때문에 결핵균 에 감염된 모든 사람이 결핵으로 진행되는 것은 아니다. 일부 환자의 경우는 잠복 결핵으로 진행되기도 하며, 일 부는 증상을 나타내지 않는 경우도 있다(Elisa et al., 2016).

이러한 결핵의 발병은 MTB의 특성뿐만 아니라 감염 된 환자의 유전적 감수성에 의하여 일어날 수도 있다 (Comstock, 1978). 실제로 이전 연구를 보면 쌍둥이에서 결핵에 대한 감수성 연구와 인종에 대한 감수성 연구가 진행되었으며, 현재에는 많은 그룹에서 유전적 상관관계

* Received: March 12, 2017 / Revised: April 26, 2017 / Accepted: May 12, 2017

${ }^{\dagger}$ Corresponding author: Sangjung Park. Department of Biomedical Laboratory Science, College of Life and Health Sciences, Hoseo University, Asan, Chungnam 31499, Korea.

Tel: +82-41-540-9967, Fax: +82-41-540-9997, e-mail: sangjung@hoseo.edu (C) The Korean Society for Biomedical Laboratory Sciences. All rights reserved.

(C) This is an Open Access article distributed under the terms of the Creative Commons Attribution Non-Commercial License (http://creativecommons.org/licenses/by-nc/3.0/) which permits unrestricted non-commercial use, distribution, and reproduction in any medium, provided the original work is properly cited. 
를 분석하는 association studies를 통하여 결핵의 발병이 면 역을 담당하는 유전자를 포함한 많은 유전자의 유전적 감 수성과 관련되어 있다고 보고했다(van der Eijk et al., 2007; Thye et al., 2010; Chimusa et al., 2014; Mahasirimongkol et al., 2012).

CD226 유전자는 CD226, PTA1 또는 DNAM-1을 암호 화하고 있는 유전자로서 염색체 18q22.3에 위치하고 있 으며, 이 유전자에 의해 발현하는 당 단백은 immunoglobulin superfamily의 일종으로 주로 $\mathrm{CD}^{+}$와 $\mathrm{CD} 8^{+} \mathrm{T}$ cell 에서 발현하며, 그 외에도 NK cell, monocyte, macrophage 와 혈소판 등에서 발현하는 것으로 알려져 있다(Shibuya et al., 1996). 이 유전자는 다양한 세포반응에 작용하고, 특 히 NK cell과 T cell의 면역반응에서 중요한 역할을 수행 한다고 알려졌다(Seth et al., 2009). 결핵과 관련하여 이전 연구에서 CD226은 genetic adjuvant로서 결핵균 감염에 있 어서 $\mathrm{Ag} 85 \mathrm{~A}$ 를 사용한 DNA 백신의 효율을 효과적으로 상승시켜 결핵균 감염을 방지할 수 있다는 보고도 있다 (Li et al., 2015).

따라서 본 연구에서는 한국인 유전체 역학 조사 사업 의 일환으로 구성되어 있는 코호트 자료를 활용해 결핵 이 발병했던 환자군과 대조군을 분류하고, 두 그룹 사이 의 결핵 발병의 차이와 $C D 226$ 유전자의 유전적 다형성 (genetic polymorphisms)과의 연관성을 확인하고자 유전적 변이에 대한 상관성 분석 연구를 시행하였다.

\section{재료 및 방법}

\section{연구대상자}

본 연구를 위한 한국인 연구대상자는 한국인 유전체 역학 조사 사업(Korean Genome and Epidemiology Study; KoGES)의 일환인 Korean Association Resource (KARE)를 기반으로 하였다(Cho et al., 2009). 경기도 안성 지역과 안 산 지역 거주자 코호트로 질병관리본부에서 한국인 보건
및 유전체 연구로 2001년도에 시작된 것이다. 40세에서 69 세 사이의 10,038 명을 모집하였으며, 이들 중에서 QC (Quality Control) 과정을 통해 분석 기준에 적합하지 않은 1,196 명은 제외되었다. 이에 따라 8,842명(남성: 4,183명, 여성: 4,659명)이 분석에 가능한 연구대상자로 남게 되었 다. 본 연구에서는 결핵에 대한 유전 변이와의 상관성 연 구가 목적이기 때문에 8,842 명의 대상자 중에서 결핵 환 자와 대조군을 선별하였다. 환자군은 결핵으로 진단을 받 은 443명을 선택하였고, 대조군은 결핵을 포함한 다른 질 환들의 진단을 받지 않은 건강한 사람 3,228 명을 대상으 로 하였다. 대조군에 포함되지 않은 다른 질환들에는 고 혈압, 당뇨병, 위염/위궤양, 알레르기질환, 심근경색, 갑상 선질환, 울혈성 심부전, 관상동맥질환, 고지혈증, 매독, 천 식, 만성폐질환, 말초혈관질환, 신장질환, 간염, 정신질환, 종양, 치매, 뇌혈관질환, 두부외상, 요로 감염, 통풍, 발기 부전, 기타 질환에 대한 진단 여부를 확인하였다. 연구대 상자 수, 남녀 구성비, 나이에 대한 정보는 Table 1에 나 타내었다. 연구윤리심의위원회(Institutional Review Board; $\mathrm{IRB}$ )에 의한 승인은 국립보건연구원에서 이루어졌으며, 모든 연구자들에게서 연구내용을 설명하고 동의서를 받 아서 진행되었다.

\section{유전형 분석과 SNP 선별}

자세한 유전형 판독과 $\mathrm{QC}$ 과정은 앞서 발표된 논문 (Cho YS, 2009)에 잘 기술되어 있다. 간략히 부연하자면, 대부분의 DNA 시료는 연구 참여자의 말초혈액에서 분리 추출하였고, 유전형 판독을 위해서는 Affymetrix GenomeWide Human SNP array 5.0 (Affymetrix, Inc., Santa Clara, CA, $\mathrm{USA})$ 을 사용하였다. 유전형 판독의 정확도는 Bayesian Robust Linear Modeling using the Mahalanobis Distance (BRLMM) algorithm (Rabbee and Speed, 2006)으로 계산하 였다. 유전형 판독 정확도가 $98 \%$ 이하이거나, $4 \%$ 이상의 높은 missing genotype call rate을 보이거나, $30 \%$ 초과의

Table 1. The subjects of tuberculosis cases and controls in the KARE study cohort

\begin{tabular}{lccc}
\hline \hline \multicolumn{1}{c}{ Characteristics } & Controls & Tuberculosis & $P$ value \\
\hline Number of subjects & 3,228 & 443 & \\
Gender [male (\%)/female (\%)] & $1,638(50.7) / 1,590(49.3)$ & $271(61.2) / 172(38.8)$ & $<0.0001$ \\
Age (M years \pm s.d.) & $51.0 \pm 0.16$ & $51.6 \pm 0.42$ & 0.213 \\
\hline
\end{tabular}

KARE, Korean Association REsource. *Significant differences in age between the controls and cases were determined by the two-tailed Student's $t$-test, and in gender rate were determined by the comparison of frequency. 
Table 2. Results of the case-control association analysis between the six SNPs in the CD226 gene on chromosome 18 and tuberculosis in the KARE subjects

\begin{tabular}{|c|c|c|c|c|c|c|c|c|c|}
\hline \multirow{2}{*}{ No. } & \multirow[b]{2}{*}{ SNP } & \multirow[b]{2}{*}{$\begin{array}{l}\text { Consequence } \\
\text { to transcript }\end{array}$} & \multirow[b]{2}{*}{$\mathrm{BP}$} & \multirow[b]{2}{*}{$\mathrm{A} 1$} & \multirow[b]{2}{*}{$\mathrm{A} 2$} & \multicolumn{2}{|c|}{ MAF } & \multirow[b]{2}{*}{ OR $(95 \% \mathrm{CI})$} & \multirow{2}{*}{$\begin{array}{l}\text { Additive } \\
P \text { value }\end{array}$} \\
\hline & & & & & & $\begin{array}{c}\text { Cases } \\
(\mathrm{n}=443)\end{array}$ & $\begin{array}{c}\text { Controls } \\
(\mathrm{n}=3,228)\end{array}$ & & \\
\hline 1 & rs1790942 & Intronic & 65692568 & $\mathrm{C}$ & $\mathrm{T}$ & 0.036 & 0.032 & $1.15(0.78 \sim 1.68)$ & 0.485 \\
\hline 2 & rs1788244 & Intronic & 65695697 & $\mathrm{~T}$ & $\mathrm{C}$ & 0.038 & 0.033 & $1.16(0.80 \sim 1.68)$ & 0.442 \\
\hline 3 & rs17081766 & Intronic & 65699795 & $\mathrm{C}$ & G & 0.079 & 0.110 & $0.70(0.54 \sim 0.90)$ & $5.4 \times 10^{-3}$ \\
\hline 4 & rs2051323 & Intronic & 65701392 & $\mathrm{~T}$ & $\mathrm{C}$ & 0.292 & 0.305 & $0.94(0.81 \sim 1.10)$ & 0.436 \\
\hline 5 & rs2051322 & Intronic & 65701566 & $\mathrm{~T}$ & $\mathrm{C}$ & 0.291 & 0.305 & $0.94(0.80 \sim 1.09)$ & 0.406 \\
\hline 6 & rs17081792 & Intronic & 65705388 & $\mathrm{C}$ & $\mathrm{T}$ & 0.096 & 0.121 & $0.78(0.61 \sim 0.98)$ & 0.035 \\
\hline
\end{tabular}

$P$-values $<0.05$ are indicated in bold. Abbreviations: A1, minor allele; $\mathrm{A} 2$, major allele; $\mathrm{BP}$, base pair; $\mathrm{CI}$, confidence interval; $\mathrm{MAF}$, minor allele frequency; OR, odds ratio; SNP, single nucleotide polymorphism. The SNP positions are based on the NCBI Build 36 human genome assembly.

heterozygosity를 가지거나, 성별 불일치가 존재하는 대상 자들은 제외하였다. 본 연구에서 분석한 $C D 226$ 유전자 영역에 존재하는 6개의 SNP은 KARE 유전형 자료에서 선별하였다. 유전자 영역은 전사체의 양 말단에서 $5 \mathrm{~kb}$ 씩 확장하여 이 범위에 존재하는 $\mathrm{SNP}$ 을 대상으로 하였다. 선별된 SNP의 염색체 상의 위치는 NCBI human genome build 36 를 기준으로 하였다(Table 2).

\section{상관성 분석과 통계 분석}

대부분의 통계 분석에는 PLINK version 1.07 (http:// pngu.mgh.harvard.edu/ purcell/plink)과 PASW Statistics version 18.0 (SPSS Inc. Chicago, IL, USA)을 사용하였다. 로지스틱 회기 분석이 결핵 환자군과 대조군에 대한 유전적 변이 와의 상관성 분석에 사용되었다. 상관성 분석은 additive genetic model을 기반으로 하였고, 유의수준은 0.05 이하를 기준으로 하였다. Haploview version 4.2 (Whitehead Institute for Biomedical Research, Cambridge, MA, USA) 프로그램 을 사용하여 KARE 유전형 정보를 바탕으로 연관불균 형(linkage disequilibrium) 블록 구조를 확인하였다. 또한, $\mathrm{CD} 226$ 의 결핵 발생과 관련된 생물학적 pathway를 검색하 기 위해서 KEGG (Kyoto Encyclopedia of Genes and Genomes, www.genome.jp/kegg/pathway.html) database에서 확인하였다.

\section{결 과}

\section{연구대상자 정보}

$\mathrm{KARE}$ 코호트 기반의 결핵 환자군과 대조군에 대한 기 본적인 정보는 Table 1에서 확인할 수 있다. 코호트 구성

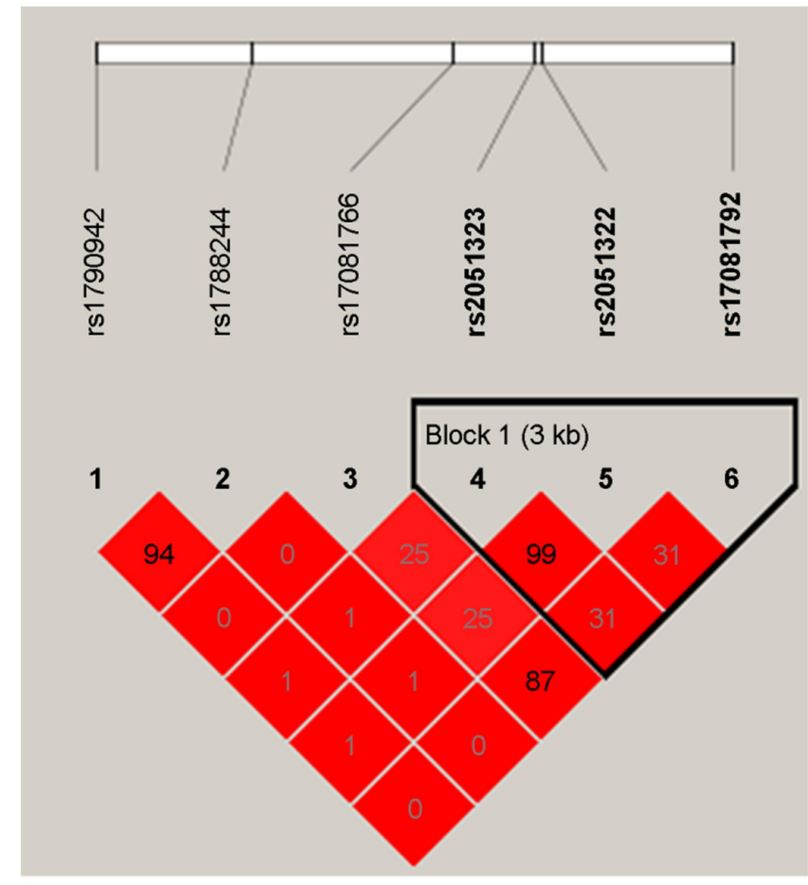

Fig. 1. Linkage disequilibrium of CD226 on chromosome 18. The six SNPs and LD structure were shown by a Haploview of LD $\left(r^{2}\right)$ based on genotyping data from 8,842 KARE subjects and are generated by using the Haploview program. 
았다. 결핵 환자군과 대조군의 평균 나이는 각각 50.1 세 와 50.6세로 통계적으로 유의한 차이가 없었다.

\section{CD226 유전자 영역의 SNP 선별과 상관성 분석 결과}

NCBI human genome build 36 를 기준으로 염색체 18 번 에서 $C D 226$ 유전자의 영역을 설정(전사체 기준으로 하여 양방향으로 $5 \mathrm{~kb}$ 씩 영역 확장)하여 $\mathrm{KARE}$ 유전형 자료에 서 6개의 SNPs (rs1790942, rs1788244, rs17081766, rs2051323, rs2051322, rs17081792)을 확인하였다(Table 2). 이렇게 선 별된 $C D 226$ 유전자의 6개 $\mathrm{SNPs}$ 을 대상으로 결핵 환자 군과 대조군에 대한 로지스틱 회귀 분석을 시행한 결과 2 개의 SNP에서 통계적으로 유의한 상관관계를 볼 수 있 었다. 가장 높은 유의 수준 $\left(P=5.4 \times 10^{-3}\right)$ 을 보이는 $\mathrm{SNP}$ 은 rs17081766으로 상대적 위험도는 0.70 에 신뢰구간은 0.54 0.90을 나타냈다. rs17081766의 minor allele frequency (MAF)를 살펴보면, 결핵 환자군에서는 $\mathrm{C}$ 염기의 빈도가 $7.9 \%$ 이고, 대조군에서는 $11.0 \%$ 로 빈도의 차이가 있어서 $\mathrm{rs} 17081766$ 의 C 염기를 보유할 경우에 결핵 발생을 감소 시키는 방향으로의 상관성이 있는 것을 알 수 있었다. 또 다른 유의한 결과를 보여주는 rs17081792도 역시 minor allele $(\mathrm{C})$ 를 가질 경우에 상대적 위험도(0.78)가 낮아지는
경향을 보여주었다(Table 2)

\section{CD226 유전자 SNP의 LD 구조}

Haploview 프로그램을 사용하여 상관 분석에 사용한 CD226 유전자 영역 6개 SNP에 대해 Linkage disequilibrium (LD) 구조를 확인하였다(Fig. 1). 그 결과 3개의 SNP (rs2051323, rs2051322, rs17081792)들이 하나의 LD 블록을 형성하고 있었다. 이 중 rs17081792는 상관 분석에서 유 의성이 있었던 $\mathrm{SNP}$ 이였고, 이 LD 블록에 속하지 않은 rs17081766은 가장 유의성이 높았던 SNP이였다. CD226 유전자의 유일한 $\mathrm{LD}$ 블록과 그 외 다른 영역에서 상관관 계가 나왔다는 사실은 $C D 226$ 유전자의 다형성이 결핵 발 병에 영향을 줄 수 있다는 사실을 뒷받침해주고 있다.

\section{$\mathrm{CD} 226$ 유전자의 KEGG pathway 검색 결과}

$\mathrm{CD} 226$ 유전자의 결핵 발생 관련성에 대해 생물학적 pathway 관점에서 살펴 보고자 KEGG database를 검색한 결과 Cell adhesion molecules이라는 signaling pathway를 확인하였다. 이 중에서 항원제시세포(Antigen presenting cells; APC)와 T cell, 혹은 Cytotoxic T cell과 감염세포와의 $\mathrm{T}$ cell receptor signaling pathway와 관련하여 $\mathrm{CD} 226$ 이 cell
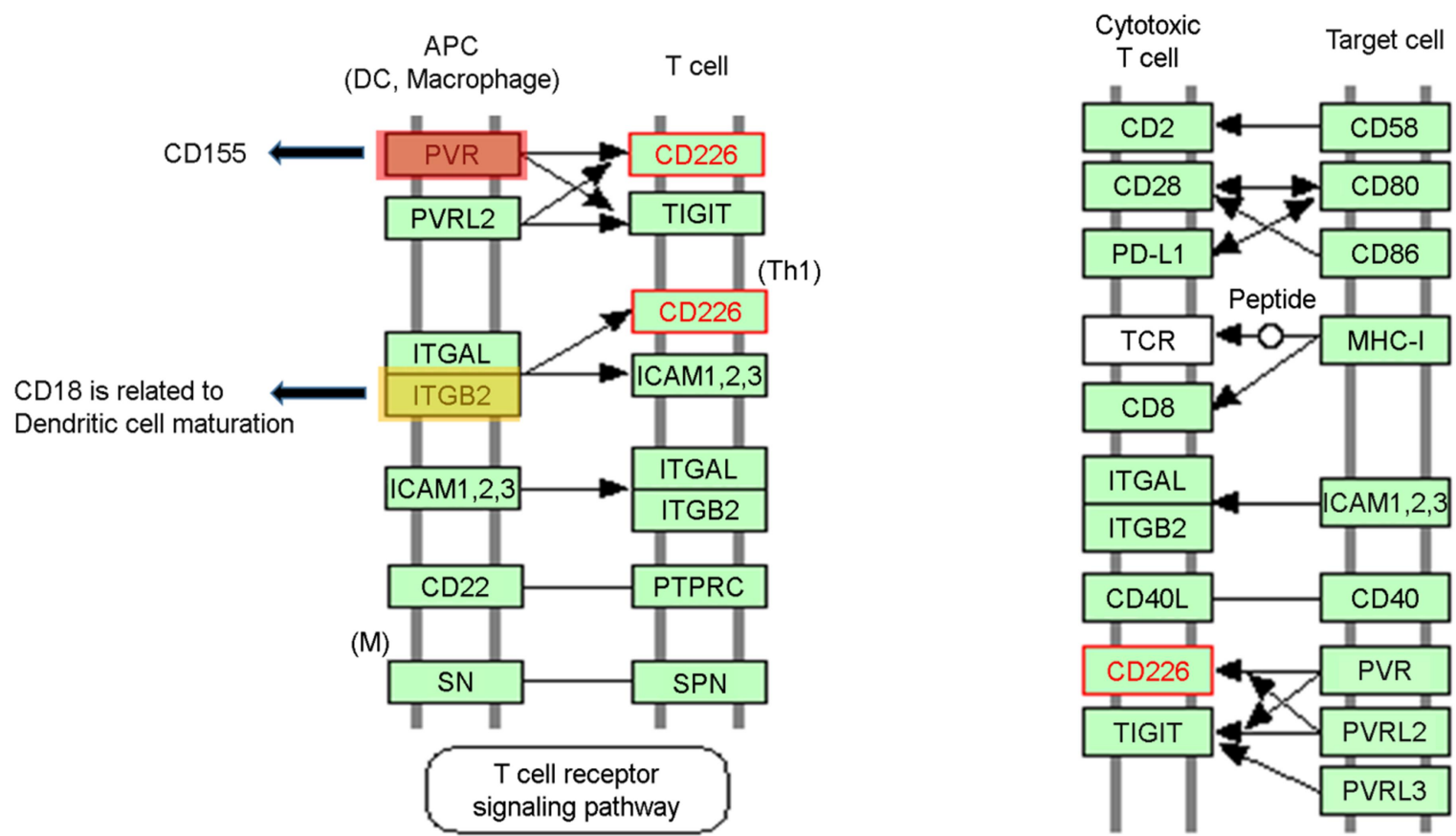

Fig. 2. The KEGG signaling pathway for the part of cell adhesion molecules. CD226 found in T cells according to KEGG is red. The interaction partners of CD226 are PVR and ITGB2 shaded in color. 
adhesion molecule로서 작용하고 있는 것을 확인할 수 있 었다(Fig. 2).

\section{고 찰}

본 연구에서는 CD226 유전자의 association 연구를 통하 여 6 개의 SNPs에서 환자군과 대조군 사이에 유전 변이의 빈도 차이를 확인해 보았다. 그 결과 두 개의 SNP에서 통계적으로 유의한 수준의 빈도 차이가 있는 것을 확인할 수 있었다. rs17081766의 C 염기를 보유한 경우에 결핵의 상대적 위험도가 0.70 로 낮아지는 것을 확인할 수 있었고, 또한 rs17081792의 C 염기를 가질 경우에도 0.78 로 상대 위험도가 낮아지는 것을 확인하였다. 또한 SNPs의 LD 구 조를 살펴보면 두 개의 유의성 있는 SNP가 서로 다른 영 역에 속하는 것을 확인할 수 있었고, 이를 통하여 CD226 유전자에 존재하는 SNP들이 결핵 발병과 통계적으로 유 의한 상관관계가 있는 것을 확인할 수 있었다.

이렇게 유의한 2개의 intronic SNP들이 과연 어떻게 $\mathrm{CD} 226$ 유전자 혹은 단백질에 영향을 미칠 것인지에 대 해 RegulomeDB (www.regulomedb.org)에서 확인해 보았다. 그 결과 helper T cell에서 rs17081766는 전사인자 결합과 DNase에 대한 반응 차이가 있음을 나타냈고, rs17081792 는 DNase peak 차이가 있음을 나타내고 있었다. 따라서, 통계적 유의성을 보이는 2개의 SNP은 T cell에서 CD226 유전자 발현에 영향을 줄 수 있는 가능성을 보여주고 있 었다.

면역반응의 관점에서 살펴보면, $\mathrm{CD} 226$ 이 초기면역반응 에서 중요한 역할을 수행하고 있는 것을 확인할 수 있었 다. 특히 Fig. 2의 KEGG database를 살펴보면, T cell에서 발현하는 $\mathrm{CD} 226$ 은 $\mathrm{APC}$ 의 $\mathrm{PVR}$ 과 ITGB2와 상호작용하는 것을 확인할 수 있었고, 또한 cytotoxic $\mathrm{T}$ cell에서 발현하는 $\mathrm{CD} 226$ 은 target cell의 PVR과 상호작용하는 것을 확인할 수 있었다. 이러한 상호작용들은 이전 연구에서 내재면역 및 획득면역 반응에 $\mathrm{CD} 226$ 이 중요한 역할을 수행하고 있다는 사실과 일치하는 것을 확인할 수 있었다(Reymond et al., 2004; Shibuya et al., 2009). 뿐만 아니라 NK cell과 cytotoxic T cell 표면에 발현한 CD226은 target 세포표면에 존재하는 CD155을 인지하고, target 세포를 제거하는 역할 을 수행한다고 알려져 있다. 이러한 상호작용은 여러 종 양의 모델에서 면역 감시 체계를 구축하는 역할을 수행하 고 있으며, 실제로 $\mathrm{CD} 226$ 이 결핍된 CTL와 NK cell이 암 세포에 대한 cytotoxicity가 감소하는 결과가 보고되기도
하였다(Seth et al., 2009; Shibuya et al., 2009; Iguchi-Manaka et al., 2008).

결핵 발병의 관점에서 살펴보게 되면 초기 $\mathrm{MTB}$ 의 감 염이 일어나면 인체 내에서는 감염에 대항하기 위해 면 역반응이 일어나고, 초기 MTB가 환자의 폐에 침입하여 alveolar macrophage에 의하여 탐식되면 Toll-like receptor 를 매개로 하는 내재면역체계가 작동하게 된다. 이런 반 응에는 호중구, NK cell, T cell과 dendritic cell의 일부가 면 역반응을 일으키며 MTB 감염에 대하여 대항하게 된다 (Guirado and Schlesinger, 2013).

그러나 이러한 초기면역 만으로는 모든 MTB 감염에 대응하지 못하며, 대부분의 경우는 $\mathrm{CD} 4$ 와 $\mathrm{CD} 8$ 계열의 $\mathrm{T}$ cell이 관여하여 감염된 $\mathrm{MTB}$ 를 포함하고 있는 granuloma form을 형성하고, 이 안에서 MTB는 사멸하게 된다. 하지 만 임상증상을 겪는 환자는 granuloma form 내에서 MTB 가 완전히 제거되지 않고, 잠복 감염으로 진행되는 경우 가 있다. 이러한 경우 환자의 면역력이 약해지게 되면 다 시 활동성 결핵으로 진행될 수 있다. 뿐만 아니라, 일부 환자의 경우는 초기면역에 실패하여 MTB를 포함하고 있 는 macrophage나 dendritic cell이 폐를 포함한 여러 장기 에 퍼지며 이차적인 폐외결핵을 유발하기도 한다(Elisa et al., 2016; Guerra et al., 2011; Esin and Batoni, 2015; Allen et al., 2013). 특히 이 중에서 CD226과 연관 지어 살펴 볼 수 있는 반응에는 $\mathrm{CD} 18 / \mathrm{ITGB} 2$ 리간드 상호작용이 있다. $\mathrm{CD} 226$ 과 ITGB2의 상호작용은 dendritic cell maturation과 연관이 있다고 알려져 있으며, dendritic cell은 MTB 감염 시 획득면역반응 시작에 매우 중요하다고 알려져 있다. 결핵에 감염된 dendritic cell은 ITGB2의 발현을 억제하고, 여러 cytokine의 분비를 늦추며, 초기면역을 형성하는 것 을 억제한다고 알려져 있다(Roberts and Robinson, 2014). 이렇듯 초기면역 반응에 실패하게 되면 환자는 결핵균을 직접 사멸하지 못하게 되면서 결핵으로 발전할 수 있도록 균을 체내에 남겨 둘 수 있게 된다. 이렇듯 같은 MTB에 대한 면역반응의 체계가 환자의 상태에 따라 다르게 작용 하여 다양한 형태의 결핵을 유발할 수 있기 때문에, 결핵 의 발병을 균 자체의 특성뿐만 아니라, MTB에 감염된 환 자의 개개인의 면역에 작용하는 유전적 차이를 확인하는 것이 결핵 발병과 연관성을 갖는다고 볼 수 있다.

그 동안 많은 연구에서 $\mathrm{MTB}$ 의 특성을 분석하여 $\mathrm{MTB}$ 의 항생제 내성, 결핵 환자에서의 $\mathrm{MTB}$ 와 $\mathrm{NTM}$ 의 동정 등 결핵의 원인균 자체에 초점을 맞춘 많은 연구들이 수 행되어 왔으며, 결핵에 감염되어 있는 환자의 면역반응을 
확인하여 진성 감염과 잠복 감염을 구분하는 연구들이 수 행되어 왔다(Jang, 2015; Hwang et al., 2005; Kim et al., 2013; Jin, 2016). 본 연구에서는 결핵 발병 원인이 MTB 자체의 특성뿐 만이 아니라 개인의 유전적 배경이 결핵 발병에 영향을 미칠 수 있다는 가능성을 제시해 주고 있으며, 이 를 통하여 결핵에 유전적으로 감수성을 가진 보균자 또 는 건강인의 관리 측면에서 환자 맞춤형 관리를 할 수 있 는 계기가 될 수 있을 것이라고 생각한다.

\section{ACKNOWLEDGEMENTS}

The clinical information and genotype data that we used were graciously provided by the Center for Genome Science, KNIH, Korea Center for Disease Control (KCDC).

\section{CONFLICT OF INTEREST}

The authors declare no conflict of interest.

\section{REFERENCES}

Allen M, Bailey C, Cahatol I, Dodge L, Yim J, Kassissa C, Luong J, Kasko S, Pandya S, Venketaraman V. Mechanisms of control of Mycobacterium tuberculosis by NK cells: Role of glutathione. Frontiers in Immunology. 2015. 6: 508.

Chimusa ER, Zaitlen N, Daya M, Möller M, van Helden PD, Mulder NJ, Price AL, Hoal EG. Genome-wide association study of ancestry-specific TB risk in the South African coloured population. Human Molecular Genetics. 2014. 23: 796 -809 .

Cho YS, Go MJ, Kim YJ, Heo JY, Oh JH, Ban HJ, Yoon D, Lee MH, Kim DJ, Park M, Cha SH, Kim JW, Han BG, Min H, Ahn Y, Park MS, Han HR, Jang HY, Cho EY, Lee JE, Cho NH, Shin C, Park T, Park JW, Lee JK, Cardon L, Clarke G, McCarthy MI, Lee JY, Lee JK, Oh B, Kim HL. A large-scale genome-wide association study of Asian populations uncovers genetic factors influencing eight quantitative traits. Nature Genetics. 2009. 41: 527-534.

Comstock GW. Tuberculosis in twins: a re-analysis of the Prophit survey. The American Review of Respiratory Disease. 1978. 117: 621-624.

Elisa P, Thomas JS, Linda P, Mark H, Daniela MC, Simone AJ, Tom HO, Claudia MD, Delia G. Correlates of tuberculosis risk: predictive biomarkers for progression to active tuberculosis. The European Respiratory Journal. 2016. 48: 1751-1763.
Esin S, Batoni G. Natural killer cells: a coherent model for their functional role in Mycobacterium tuberculosis infection. Journal of Innate Immunity. 2015. 7: 11-24.

Guerra C, Morris D, Sipin A, Kung S, Franklin M, Gray D, Tanzil M, Guilford F, Khasawneh FT, Venketaraman V. Glutathione and adaptive immune responses against Mycobacterium tuberculosis infection in healthy and HIV infected individuals. PLoS One. 2011. 6: e28378.

Guirado E, Schlesinger LS. Modeling the Mycobacterium tuberculosis granuloma - the critical battlefield in host immunity and disease. Frontiers in Immunology. 2013. 4: 98.

Hwang JW, Jeong EY, Choi YI, Bae K, Song TS, Cho SN, Lee H. Molecular analysis of isoniazid-resistance related genes of Mycobacterium tuberculosis isolated from Korea. Journal of Experimental Biomedical Science. 2005. 11: 455-465.

Iguchi-Manaka A, Kai H, Yamashita Y, Shibata K, Tahara-Hanaoka S, Honda S, Yasui T, Kikutani H, Shibuya K, Shibuya A. Accelerated tumor growth in mice deficient in DNAM-1 receptor. The Journal of Experimental Medicine. 2008. 205: 2959-2964

Jang HS. Identification of Mycobacteria using polymerase chain reaction and sputum sample. Korean Journal of Laboratory Science. 2015. 47: 83-89.

Jin HW. RT-PCR targeting rpoB mRNA for drug susceptibility test of Mycobacterium tuberculosis in liquid culture. Biomedical Science Letters. 2016. 22: 215-219.

KCDC. Korean Tuberculosis Report. 2015

http://www.cdc.go.kr/CDC/contents/CdcKrContentView.jsp?cid= 61919\&menuIds=HOME001-MNU1130-MNU1890-MNU1 891-MNU1898

Kim S, Cho JE, Kim H, Lee D, Jeon B, Lee H, Cho SN, Kim YK, Lee H. Comparison of Mycobacterium tuberculosis specific antigen stimulation time for performing interferon gamma mRNA assay for detecting latent tuberculosis infection. Journal of Experimental Biomedical Science. 2013. 19: 90-97.

Li Y, Yang F, Zhu J, Sang L. Han X, Wang D, Shan F, Li S, Sun X, $\mathrm{Lu}$ C. CD226 as a genetic adjuvant to enhance immune efficacy induced by Ag85A DNA vaccination. International Immunopharmacology. 2015. 25: 10-18.

Mahasirimongkol S, Yanai H, Mushiroda T, Promphittayarat W, Wattanapokayakit S, Phromjai J, Yuliwulandari R, Wichukchinda N, Yowang A, Yamada N, Kantipong P, Takahashi A, Kubo M, Sawanpanyalert P, Kamatani N, Nakamura Y, Tokunaga K Genome-wide association studies of tuberculosis in Asians identify distinct at-risk locus for young tuberculosis. Journal 
of Human Genetics. 2012. 57: 363-367.

Rabbee N, Speed TP. A genotype calling algorithm for affymetrix SNP arrays. Bioinformatics. 2006. 22: 7-12.

Reymond N, Imbert AM, Devilard E, Fabre S, Chabannon C, Xerri L, Farnarier C, Cantoni C, Bottino C, Moretta A, Dubreuil P, Lopez M. DNAM-1 and PVR regulate monocyte migration through endothelial junctions. The Journal of Experimental Medicine. 2004. 199: 1331-1341.

Roberts LL, Robinson CM. Mycobacterium tuberculosis infection of human dendritic cells decreases integrin expression, adhesion and migration to chemokines. Immunology. 2014. 141: 39-51.

Seth S, Georgoudaki AM, Chambers BJ, Qiu Q, Kremmer E, Maier MK, Czeloth N, Ravens I, Foerster R, Bernhardt G. Heterogeneous expression of the adhesion receptor $\mathrm{CD} 226$ on murine $\mathrm{NK}$ and $\mathrm{T}$ cells and its function in NK-mediated killing of immature dendritic cells. Journal of Leukocyte Biology. 2009. 86: 91-101.

Shibuya A, Campbell D, Hannum C, Yssel H, Franz-Bacon K, McClanahan T, Kitamura T, Nicholl J, Sutherland GR, Lanier LL, Phillips JH. DNAM-1, a novel adhesion molecule involved in the cytolytic function of T lymphocytes. Immunity. 1996.
4: $573-581$

Thye T, Vannberg FO, Wong SH, Owusu-Dabo E, Osei I, Gyapong J, Sirugo G, Sisay-Joof F, Enimil A, Chinbuah MA, Floyd S, Warndorff DK, Sichali L, Malema S, Crampin AC, Ngwira B, Teo YY, Small K, Rockett K, Kwiatkowski D, Fine PE, Hill PC, Newport M, Lienhardt C, Adegbola RA, Corrah T, Ziegler A; African TB Genetics Consortium; Wellcome Trust Case Control Consortium, Morris AP, Meyer CG, Horstmann RD, Hill AV. Genome-wide association analyses identifies a susceptibility locus for tuberculosis on chromosome 18q11.2. Nature Genetics. 2010. 42: 739-741.

Van der Eijk EA, Van de Vosse E, Vandenbroucke JP, Van Dissel JT. Heredity versus environment in tuberculosis in twins: the 1950s UK Prophit Survey Simonds and Comstock revisited. American Journal of Respiratory and Critical Care Medicine. 2007. 176: $1281-1288$

http://dx.doi.org/10.15616/BSL.2017.23.2.89

Cite this article as: Jin HS, Park SJ. Association of the CD226 Genetic Polymorphisms with Risk of Tuberculosis. Biomedical Science Letters. 2017. 23: 89-95. 